\title{
Effect of concrete tensile strenght in non linear analyses of 2D structures - a comparison between three commercial finite element softwares
}

\author{
Gabriele Bertagnoli Dario La Mazza Prof Giuseppe Mancini
}

\begin{abstract}
Non-linear finite element method (FEM) allows to take into account material and geometrical non-linearities in the simulation of the behaviour of reinforced concrete structures. However, the accuracy of the numerical solution with respect to experimental tests is often questionable, especially in the case of 2D and 3D structures. Several competitions showed in the past significant scatter of the predicted results with respect to the correct ones. Even though internationally well-known computer softwares can be used to predict the structural response, the uncertainty of the numerical simulation cannot be neglected. Therefore, the application of finite element models to the assessment of concrete structures requires a proper investigation of the uncertainty related to the results of the simulations. This paper presents a comparison of numerical simulations of sixteen case studies taken from past experimental tests and modelled with three commercial non-linear softwares. The purpose of the investigation is to show how significant could be the difference between the experimental and numerically evaluated failure load and displacement in function of the code used and the variation of only one material parameter.
\end{abstract}

Keywords Non-linear analysis, FEM, Reinforced concrete structures, model uncertainties

\section{INTRODUCTION}

One of the innovative issues of the Model Code 2010 [1] (fib, 2010a and fib, 2010b) is the safety format for non-linear analysis.

The document allows the designer to check the structural safety in the domain of the actions through the inequality $F_{d}<R_{d}$, where $F_{d}$ and $R_{d}$ are the design values of the actions and structural resistance, respectively.

The design value $R_{d}$ accounts for uncertainties related to the material properties, dimensions and modelling of the overall behaviour. With respect to the evaluation of the structural behaviour, the Model Code 2010 suggests the use of non-linear solution methods (i.e. the Finite Element Method - FEM) and material models reflecting the expected real behaviour of the structure. A question arises: how accurately does the FEM model represent the real structural behaviour? The topic is of great concern, because the safety verification depends on the assumptions underlying the FEM model developed by the engineer. The modelling choices are responsible of the scatter in the results, as reported by Belletti et. al. [2].

Gabriele Bertagnoli

DISEG

Politecnico di Torino

Torino, Italy

Dario La Mazza

DISEG

Politecnico di Torino

Torino, Italy

Prof Giuseppe Mancini

DISEG

Politecnico di Torino

Torino, Italy
This paper presents an investigation about the difference between the real behaviour of $2 \mathrm{D}$ reinforced concrete structures and the predicted one by structural analysis softwares. Three internationally well-known commercial programs for non-linear analysis of structures have been used to simulate the structural behaviour up to failure of 16 structures. The comparison of the three programs in terms of accuracy is not within the scope of the paper, therefore, they will be named as code A, B and C.

The present paper continues the work done by the same authors [3] on simpler structures and can be seen as a second step of a research activity aiming at the probabilistic characterization of the uncertainties concerning the prediction of the structural behaviour by means of the FEM.

The prediction of the structural response through a FEM analysis is uncertain to some extent. Any numerical model can be regarded only as an approximation of the real behaviour of structures. The model aims to describe the essential characteristics of the overall behaviour, while other aspects are neglected. Consequently, the predicted and the real behaviours may be slightly different.

Schlune et al. [4] presented a review of round robin exercises and modelling competitions concerning structural elements which failed in compression, in bending (with under- and overreinforced sections) or in shear. The results provided by the participants are distributed around the response of the laboratory tests with a coefficient of variation ranging from $5 \%$ (case of flexural failure with under-reinforced cross-section) to $40 \%$ (case of shear failure due to crushing of concrete).

\section{CASE STUDIES}

The 16 laboratory tests chosen to investigate the difference between the numerical results of n.l analyses are taken from classic experimental campaigns done by Leonhardt and Walther [5], Foster and Gilbert [6], Lefas and Kotsovos [7] and Fihlo [8].

The Leonhardt and Walther walls [5] WT2, WT3, WT4, WT6 and WT7 (Figs. 1-4) are $1.6 \mathrm{~m}$ wide and high. The walls have a uniform thickness of $0.1 \mathrm{~m}$ and they work in simply supported static scheme. The reinforcement consists of horizontal and vertical stirrups and additional bars in the bottom part of the structure. Concrete compressive strength varies between 26.7 and $28.7 \mathrm{MPa}$, while the mechanical properties of reinforcement depend on the diameter of the bar. The walls WT2, WT3, WT4 are loaded from the top and they differ for the amount of reinforcement in the bottom part of the structure. The horizontal and vertical rebars have diameter of $5 \mathrm{~mm}$ and spacing of 26 $\mathrm{mm}$. The structures WT6 and WT7 are loaded from the bottom and differ in the distribution of the applied loads and bottom reinforcement. 
The Foster and Gilbert deep beams [6] B2.0-1, B2.0-3, B3.0-1, B2.0A-4 and B3.0A-4 (Figs. 5-6) are $0.7 \mathrm{~m}$ deep, $0.125 \mathrm{~m}$ thick and simply supported at the extremities. The beams B2.0-1, B2.0-3, B3.01 differ from the beams B2.0A-4 and B3.0A-4 for the load arrangement. The main tensile reinforcement consists of six longitudinal bars $\phi 20$. The web reinforcement is realized with $\phi 6.3 / 75 \mathrm{~mm}$ in the transverse direction and $\phi 6.3 / 135 \mathrm{~mm}$ in the longitudinal direction. Concrete compressive strength is between 78 and $88 \mathrm{MPa}$.
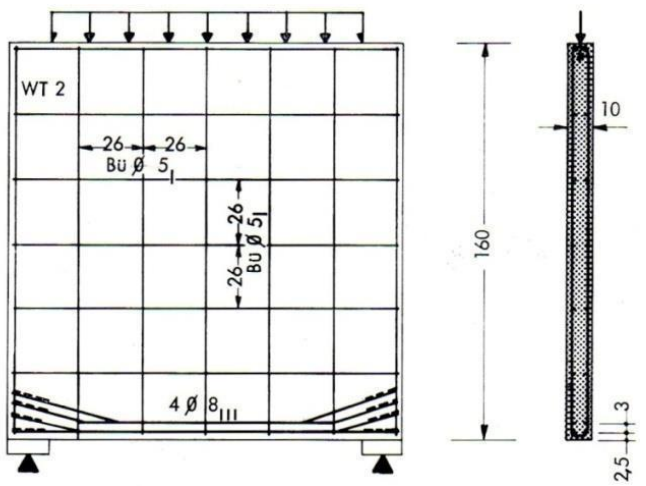

Figure 1. Leonhardt and Walther wall WT2
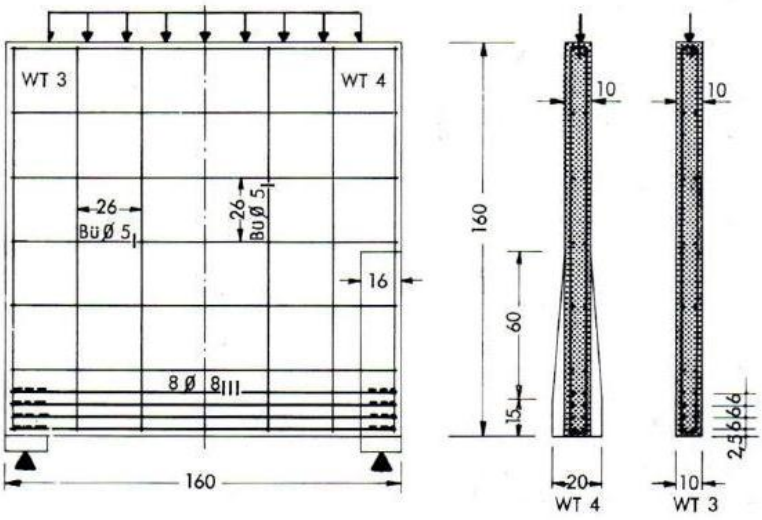

Figure 2. Leonhardt and Walther wall WT3 and WT4.
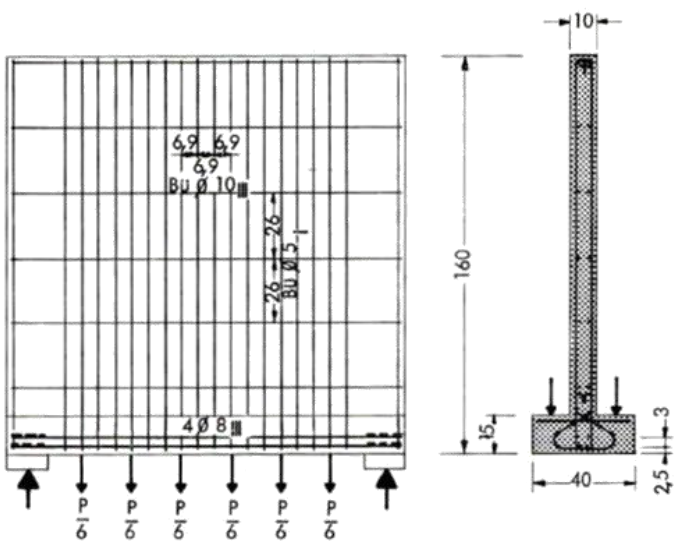

Figure 3. Leonhardt and Walther wall WT6
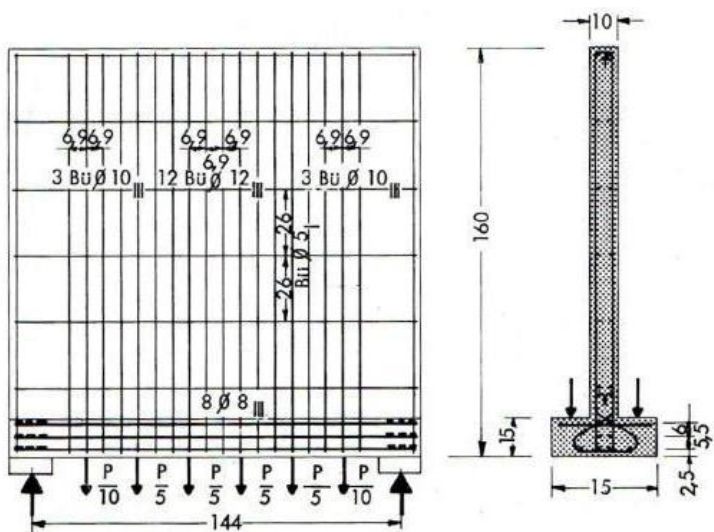

Figure 4. Leonhardt and Walther wall WT7

Lefas and Kotsovos wall [7] SW11 (Fig. 7) is $1.2 \mathrm{~m}$ high, $0.75 \mathrm{~m}$ wide, $0.07 \mathrm{~m}$ thick and stiffened by $0.2 \mathrm{~m}$ thick upper and lower ribs. The structure is fully restrained at the base and loaded by a horizontal force at the top. Concrete compressive strength is $43 \mathrm{MPa}$, while the reinforcement consists of $2 \phi 6.25 / 80 \mathrm{~mm}$ horizontal bars and $2 \phi 8 / 60 \mathrm{~mm}$ vertical bars.

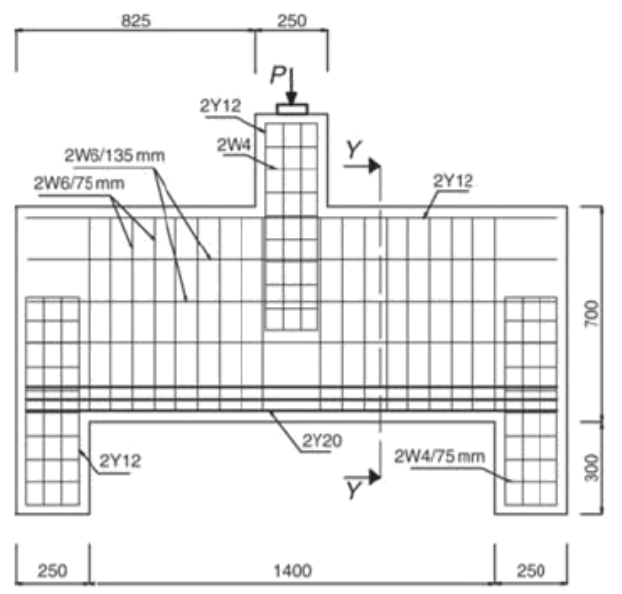

Figure 5. Foster and Gilbert beams B2.01, B2.03 and B3.01.

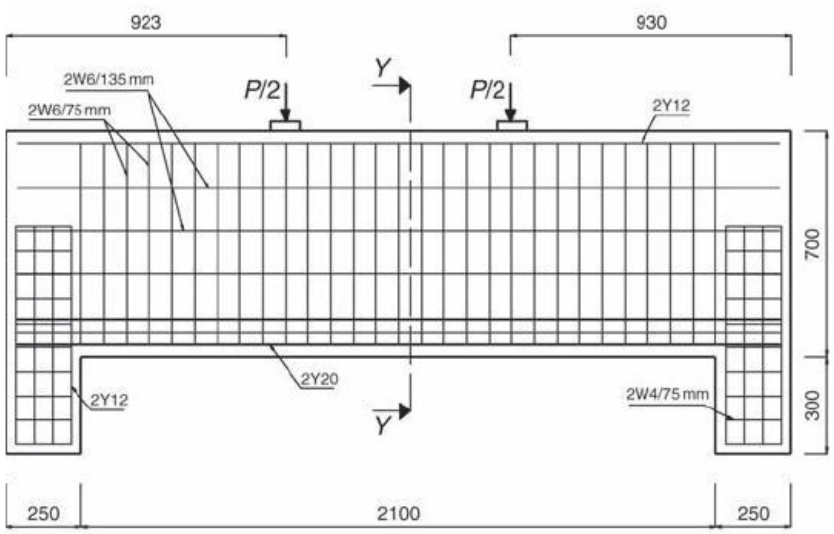

Figure 6. Foster and Gilbert beams B2.0A-4 and B3.0A-4. 
Proc. of the Third Intl. Conf. on Advances in Civil, Structural and Construction Engineering - CSCE 2015 Copyright (C) Institute of Research Engineers and Doctors, USA .All rights reserved. ISBN: 978-1-63248-079-8 doi: 10.15224/ 978-1-63248-079-8-104

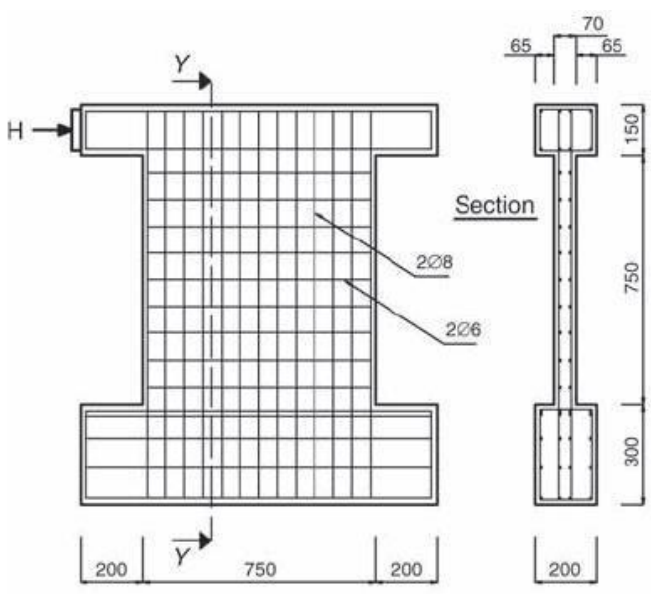

Figure 7. Lefas and Kotsovos wall SW11.

Filho walls [8] MB11AA, MB11AE, MB1EE, MB1EE1 and MB4EE (Figs. 8-12) are $1.35 \mathrm{~m}$ high, $1.0 \mathrm{~m}$ wide, $0.12 \mathrm{~m}$ thick and stiffened by a $0.2 \mathrm{~m}$ thick and $0.5 \mathrm{~m}$ deep base. They are fully restrained at the base and loaded by a horizontal force at the top. The structures are also characterized by a $0.4 \mathrm{~m}$ wide square opening. Concrete compressive strength is between 39 and $42 \mathrm{MPa}$, while the reinforcement layout varies significantly from one structure to the others.

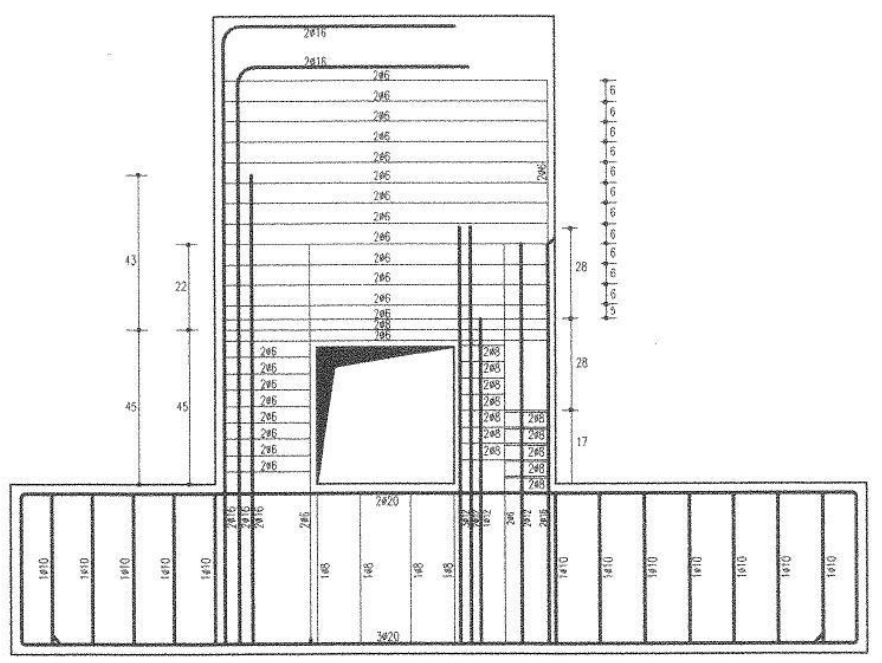

Figure 8. Filho wall MB11AA.

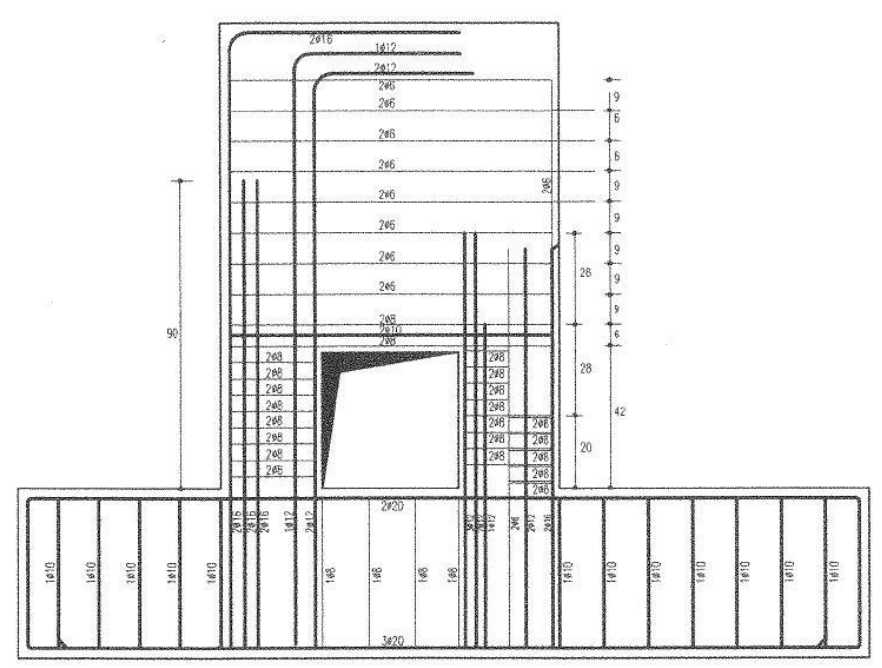

Figure 9. Filho wall MB11AE

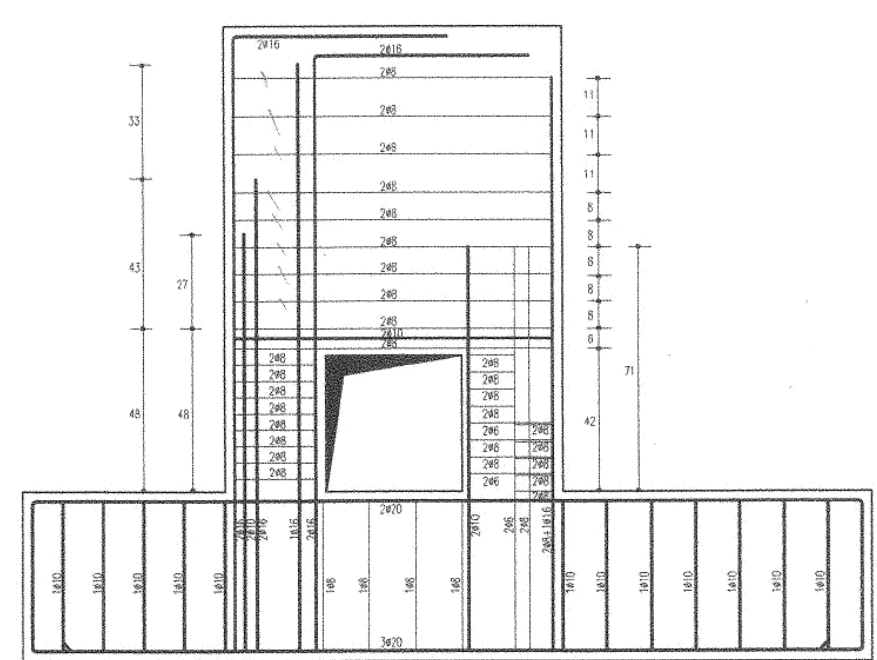

Figure 10. Filho wall MB1EE

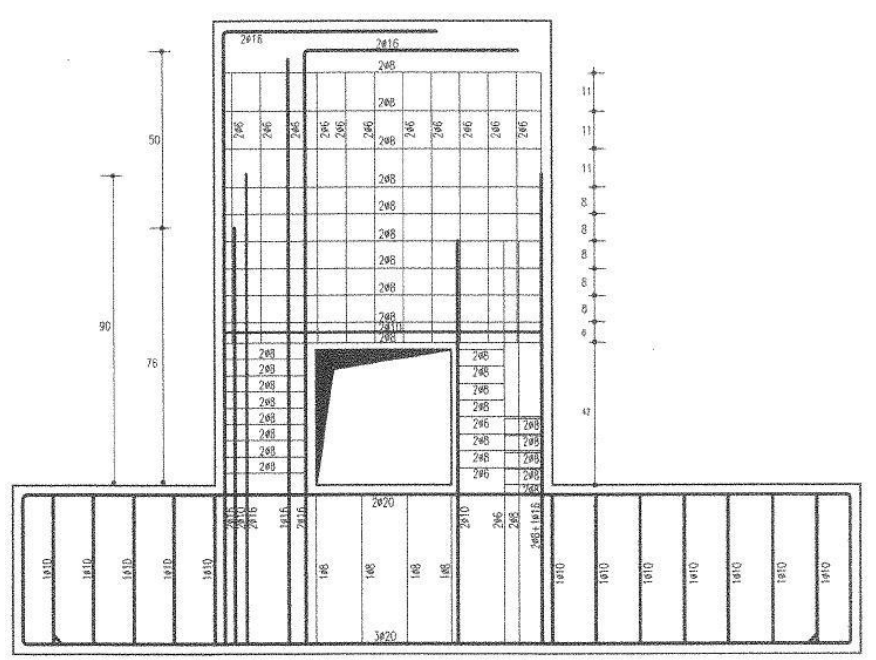

Figure 11. Filho wall MB1EE1

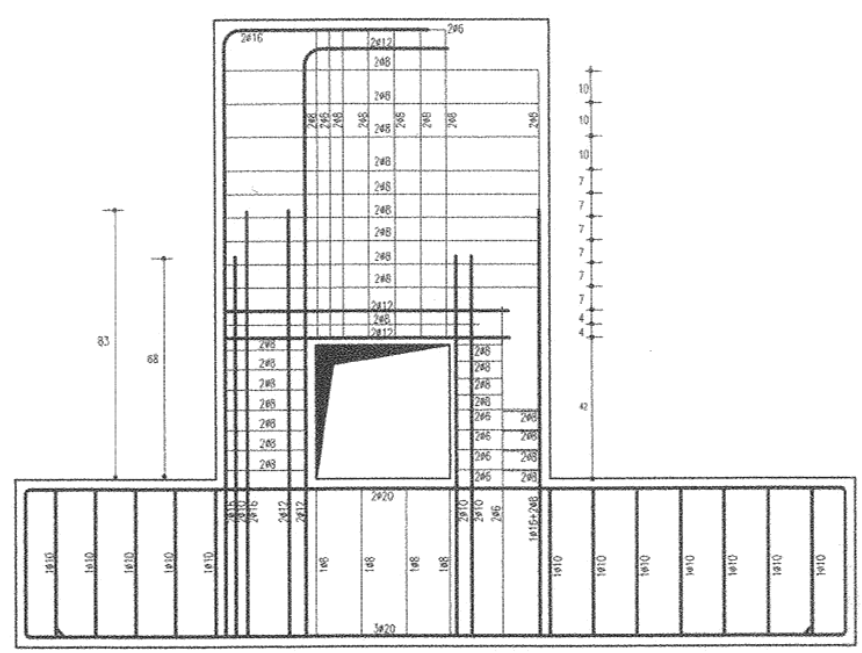

Figure 12. Filho wall MB4EE

\section{FINITE ELEMENT FORMULATION}

Quadrilateral iso-parametric plane stress elements are used to represent the concrete bodies in all the three 
softwares; such elements are also used to model the regions where the thickness of the beams are variable simply changing the elements thickness.

Linear interpolation as shown in equation (1) and $2 \times 2$ Gauss integration is used.

$$
u(\xi, \eta)=a_{0}+a_{1} \xi+a_{2} \eta+a_{3} \xi \eta
$$

Average element dimensions where chosen approximately close to $10 \mathrm{~cm}$ in order to consider concrete as a homogeneous material.

\section{MATERIALS MODELS FOR CONCRETE}

The aim of the present work is to show the difference in the response of three softwares when only one material parameter is changed.

The chosen parameter is the post-peak tensile behaviour of concrete, considering elastic-brittle, elastic-plastic and a linear tension softening. No other material properties are changed in order to have only one varying parameter.

The main mechanical characteristics of the materials models used for concrete in the three codes are presented in the following paragraphs.

\section{A. Mono-axial constitutive law in compression}

The constitutive law of concrete in compression used in software A is written in equation (2) and is pictured in figure 12. The input parameters used to define the curve were chosen by the user according to EN 1992-1-1 [9].

$$
\begin{gathered}
\frac{\sigma}{f_{c}}=\frac{\left(\frac{E_{c}}{E_{S}}\right)\left(\frac{\varepsilon}{\varepsilon_{c}}\right)}{1+A\left(\frac{\varepsilon}{\varepsilon_{c}}\right)+B\left(\frac{\varepsilon}{\varepsilon_{c}}\right)^{2}+C\left(\frac{\varepsilon}{\varepsilon_{c}}\right)^{3}} \\
A=\frac{\left[\frac{E_{c}}{E_{u}}+\left(p^{3}-2 p^{2}\right) \frac{E_{c}}{E_{s}}-\left(2 p^{3}+3 p^{2}+1\right)\right]}{\left[\left(p^{2}-2 p+1\right) p\right]} \\
B=\left[\left(2 \frac{E_{c}}{E_{S}}-3\right)-2 A\right] \\
C=\left[\left(2-\frac{E_{c}}{E_{S}}\right)+A\right] \\
E_{S}=\frac{f_{c}}{\varepsilon_{c}} \\
E_{u}=\frac{f_{u}}{\varepsilon_{u}} \\
p=\frac{\varepsilon_{u}}{\varepsilon_{c}}
\end{gathered}
$$

where:

$E_{c} \quad$ zero-stress tangent Young modulus;

$E_{s} \quad$ secant Young modulus of concrete corresponding to peak strength;

$E_{u}$ secant Young modulus of concrete corresponding to ultimate strength;

$\varepsilon \quad$ strain;

$\varepsilon_{c} \quad$ peak strain;

$\varepsilon_{u} \quad$ ultimate strain;

$\sigma \quad$ stress;

$f_{c} \quad$ peak strength;

$f_{u} \quad$ ultimate strength;

$p \quad$ ratio between ultimate and peak strain;

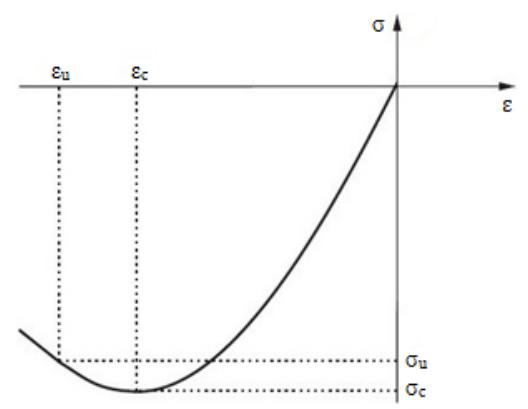

Figure 13. Software A: mono-axial constituitve law of concrete in compression

The constitutive law of concrete in compression used in software B is taken from MC1990 [10], it is written in equation (9) and is pictured in figure 14.

$$
\begin{gathered}
\sigma=f_{c} \frac{k x-x^{2}}{1+(k-2) x} \\
x=\frac{\varepsilon}{\varepsilon_{c}} \\
k=\frac{E_{0}}{E_{c}}
\end{gathered}
$$

where:

$\sigma \quad$ stress;

$f_{c} \quad$ peak strength;

$x$ non dimensional strain;

$\varepsilon \quad$ strain;

$\varepsilon_{c} \quad$ peak strain;

$k \quad$ shape parameter;

$E_{0} \quad$ zero-stress tangent Young modulus;

$E_{c} \quad$ secant Young modulus of concrete corresponding to peak strength;

After the peak, the law linearly decreases and can be described by a model based on the energy dissipated or through a model based on the ultimate strain $\varepsilon_{u}$

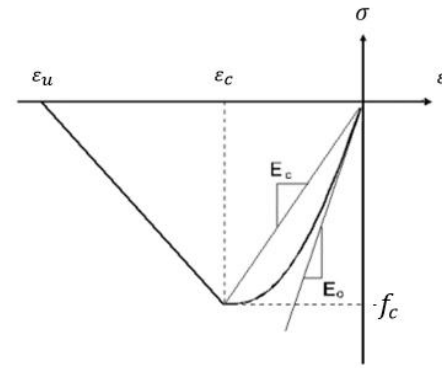

Figure 14. Software B: mono-axial constituitve law of concrete in compression

The nonlinear function proposed by Thorenfeldt et al. in 1987 [11] and defined by equation (12) is used in software C (see figure 15).

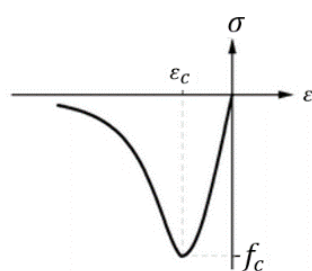

Figure 15. Software C: mono-axial constituitve law of concrete in compression 


$$
\begin{gathered}
\sigma=-f_{c} \frac{\varepsilon}{\varepsilon_{c}}\left(\frac{n}{n-\left(1-\left(\frac{\varepsilon}{\varepsilon_{c}}\right)^{n k}\right)}\right) \\
n=0.8+\frac{R_{c}}{17} \\
k=\left\{\begin{array}{cc}
1 & 0>\varepsilon>\varepsilon_{c} \\
0.67+\frac{R_{c}}{62} & \varepsilon \leq \epsilon_{c}
\end{array}\right.
\end{gathered}
$$

where:

$\sigma \quad$ compression stress;

$f_{c} \quad$ compressive strength;

$\varepsilon \quad$ compressive strain;

$\epsilon_{c} \quad$ peak compressive strain

$R_{c} \quad$ mono-axial cubic compressive strength;

$n, k$ model parameters;

The stress-strain relations presented in equations (2), (9) and (12) assume monotonic loading conditions. For unloading conditions and loading back to the stress state from which unloading occurred, the initial tangent Young's modulus at zero stress is used.

\section{B. Two-dimensional constitutive law in compression}

In software A the mono-axial constitutive law of concrete in compression is modified taking into account variation of the peak compressive and ultimate strength and relative strains in function of generalized tri-axial state of stress.

This phenomenon can lead to compression softening as shown in figure 16 when the material is subjected to tensile stresses orthogonal to the main direction of compression or to compression hardening when the material gets close to hydrostatic state of stress.

The background formulation is not reported here in detail, being it a characteristic of software A and not being fundamental for the purpose of this work.

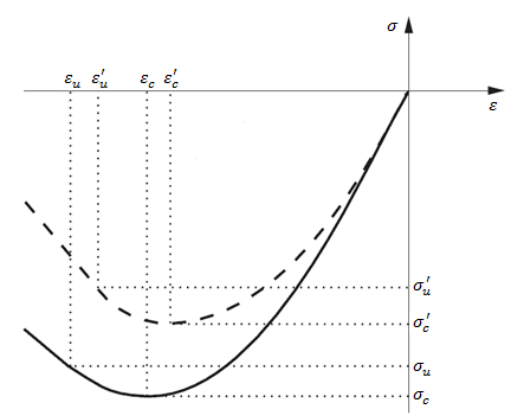

Figure 16 Software A: two dimensional constituitve law of concrete in compression

In software B, MC1990 law is modified in the biaxial compressive stress state, taking into account a proportional increase of the stress path following the failure domain presented in paragraph $\mathrm{C}$.

On the other hand, MC1990 law is modified to take into account compressive strength reduction due to orthogonal tensile actions. The model is based on the approach defined by Vecchio and Collins in 1982 [12], modified according to Kolleger theory [13] using the Gaussian function shown in equation (22) and figure 17.

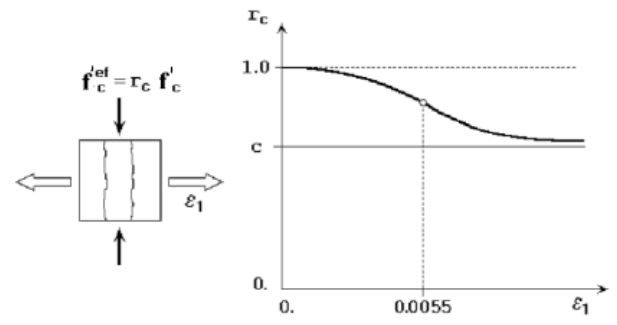

Figure 17. Software B: reduction factor for compressive strength

$$
\begin{gathered}
f_{c}{ }^{\prime e f}=f_{c}{ }^{\prime} r_{c} \quad\left(c \leq r_{c} \leq 1\right) \\
r_{c}=c+(1-c) e^{-\left(128 \varepsilon_{u}\right)^{2}}
\end{gathered}
$$

where:

$f_{c}{ }^{\prime e f}$ compressive strength in biaxial tension-compression;

$f_{c}{ }^{\prime} \quad$ mono-axial cylindrical compressive strength;

$r_{c}$ reduction factor for compressive strength due to orthogonal tensile strains;

c lower limit for the reduction factor.

The user can choose the parameter $c$ that provides the minimum value of compressive strength $f_{c}^{\text {'ef }}$ for large transversal strains. In this work it was assumed equal to 0.45 as suggested by Kollegger.

The Thorenfeld law used in software $\mathrm{C}$ can be modified to take account of lateral cracking or confinement. The presence of cracks affects the collapse mechanism, reducing the compressive strength of the material, whereas transverse confinement enhances it.

Concrete subjected to compressive stresses shows a pressuredependent behavior, i.e., the strength and ductility increase with increasing isotropic stress.

Due to the lateral confinement, the compressive stress-strain relationship is modified to incorporate the effects of the increased isotropic stress (see figure 18).

To model the lateral confinement effect, the parameters of the compressive stress-strain function, $\mathrm{f}_{\mathrm{c}}$ and $\varepsilon_{\mathrm{c}}$, are enhanced by means of Selby [14] peak stress factor $K_{\sigma}$ and peak strain factor $K_{\varepsilon}$ as follows:

$$
\begin{aligned}
& f_{c c}=K_{\sigma} f_{c} \\
& \varepsilon_{c c}=K_{\varepsilon} \varepsilon_{c}
\end{aligned}
$$

Where $K_{\sigma}=K_{\varepsilon}$ are determined according to Hsieh-Ting-Chen [15] failure criterion (1979).

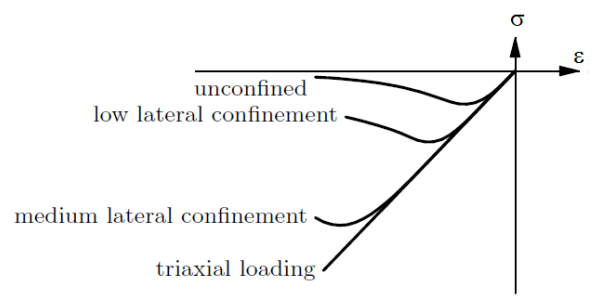

Figure 18. Software C: effect of confinement

The effect of transverse cracking on compressive behavior is taken into account using two reduction factors $\beta_{\sigma_{c r}}$ and that reduce respectively the peak stress $f_{c}$ and the peak strain $\varepsilon_{c}$ as shown in equations (26) and (27).

$$
\begin{aligned}
& f_{c t}=\beta_{\sigma_{c r}} f_{c} \\
& \varepsilon_{c t}=\beta_{\varepsilon_{c r}} \varepsilon_{c}
\end{aligned}
$$


Where $\beta_{\sigma_{c r}}$ is function of the tensile lateral strain $\alpha_{\text {lat }}$ as shown in figure 19 , whereas $\beta_{\varepsilon_{c r}}=1$.

This model has been developed on the basis of the Modified Compression Field Theory proposed by Vecchio and Collins in 1986 [16].

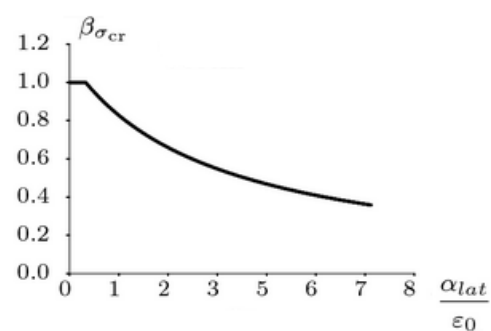

Figure 19. Software C: effect of transverse tensile strain

\section{Two dimensional failure criteria}

In software A the multi-axial failure criterion is obtained by means of linearization of the failure domain proposed by Kupfer et al. [17] as represented in Figure 20.

Once defined the principal stresses $\sigma_{p i}(\mathrm{i}=1,2)$ with $\sigma_{p 1}>\sigma_{p 2}$ and assuming $\sigma_{p 1}$ constant, the stress $\sigma_{p 2}$ that causes the concrete failure for crushing can be evaluated by means of the failure curve: this stress is called $\sigma_{c}^{\prime}$.

The parameters $\sigma_{u}^{\prime}, \varepsilon_{c}^{\prime}$ e $\varepsilon_{u}^{\prime}$ can be calculated respectively using equations (29), (30) and (31) in function of the parameter $\gamma_{1}$ given by equation (28) and of shape parameters $C_{1}$ and $C_{2}$.

$$
\begin{gathered}
\gamma_{1}=\frac{\sigma_{c}^{\prime}}{\sigma_{c}} \\
\sigma_{u}^{\prime}=\gamma_{1} \sigma_{u} \\
\varepsilon_{c}^{\prime}=\left(C_{1} \gamma_{1}^{2}+C_{2} \gamma_{1}\right) \varepsilon_{c} \\
\varepsilon_{u}^{\prime}=\left(C_{1} \gamma_{1}^{2}+C_{2} \gamma_{1}\right) \varepsilon_{u}
\end{gathered}
$$

Suggested values for the parameters $C_{1}$ and $C_{2}$ are: $C_{1}=1.4, C_{2}=-0.4$.

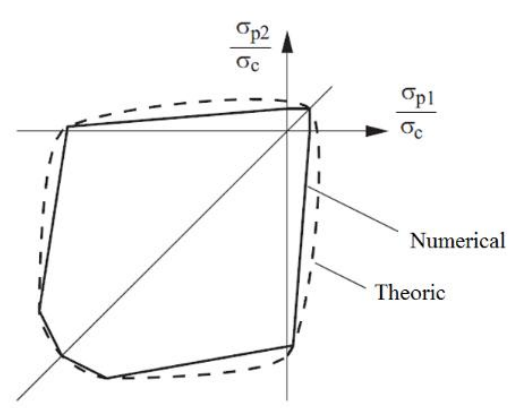

Figure 20. Software A: biaxial failure domain

Also software B implements Kupfer failure criterion [17], but, in this case without simplifications as shown in figure 21.

The equation that define the domain in the regions compression-compression, tension-compression and tensiontension are respectively the (32), (34) and (36).

$$
\begin{gathered}
f_{c}^{\prime e f}=\frac{1+3.65 a}{(1+a)^{2}} f_{c}{ }^{\prime} \\
a=\frac{\sigma_{c 1}}{\sigma_{c 2}} \\
f_{c}{ }^{\prime e f}=f_{c}^{\prime} r_{e c}
\end{gathered}
$$

$$
\begin{gathered}
r_{e c}=\left(1+5.3278 \frac{\sigma_{c 1}}{f_{c}{ }^{\prime}}\right) \\
f_{t}{ }^{\prime e f}=f_{t}{ }^{\prime} r_{e t} \\
r_{e t}=\left(1-0.95 \frac{\sigma_{c 2}}{f_{c}{ }^{\prime}}\right)
\end{gathered}
$$

where:

$f_{c}^{\prime e f} \quad$ compressive strength under biaxial state of stress;

$\sigma_{c 1}, \sigma_{c 2} \quad$ main stresses;

$f_{c}^{\prime} \quad$ uniaxial cylindrical compressive strength;

$r_{e c}$ reduction factor for the compressive strength $\left(0.9 \leq r_{e c} \leq 1\right)$

$r_{e t} \quad$ reduction factor for tensile strength $\left(0.9 \leq r_{e c} \leq 1\right)$.

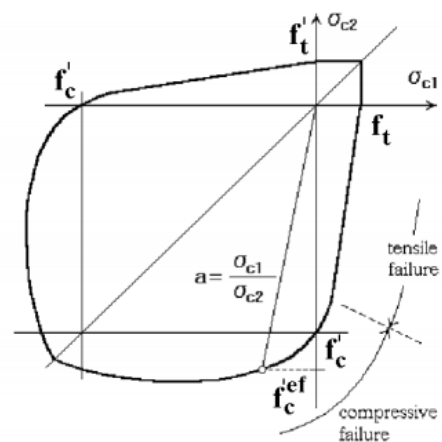

Figure 21. Software B: biaxial failure domain

\section{Fixed crack model}

Smeared fixed crack direction model [18] [19] [20] is adopted in all the softwares: the crack direction is defined at first cracking and does not change during the following load steps. Shear stresses can be present on the crack surface by means of reduction of shear stiffness after cracking (shear retention factor $\beta=0.2$ ).

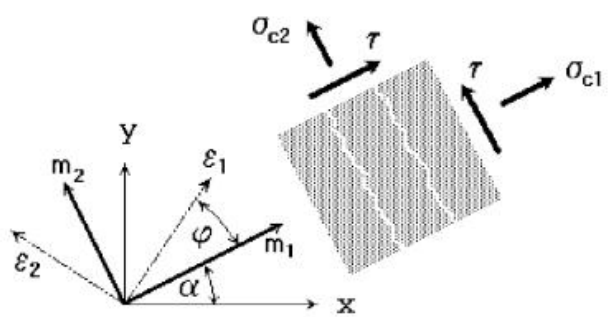

Figure 22. Fixed crack model

The directions of principal stresses and principal strains coincide in uncracked field. After cracking the material becomes orthotropic with a strong axis $\mathrm{m}_{2}$ parallel to the cracks and a weak axis $m_{1}$ orthogonal to them. In such condition the directions of principal strains $\varepsilon_{1}$ e $\varepsilon_{2}$ do not coincide any more with the orthotropy axis $m_{1}$ and $m_{2}$ because of shear friction present on cracks as shown in figure 22 .

\section{E. Tension softening models}

In all the softwares three different constitutive laws for concrete in tension are considered (see figure 23). Each law leads to a different amount of rebar tension stiffening modifying the stiffness of the regions around tensile reinforcement. 
The three laws considered are: elastic-brittle, elastic-plastic and a linear tension softening. The first two models can be regarded as as limit models, while the extent of the linear softening branch of the third is the only parameter the researcher could change within the experiment set up for this paper in order to best fit the experimental load-deflection curve.

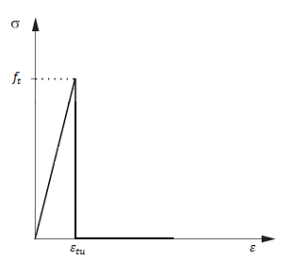

$\mathrm{a}$

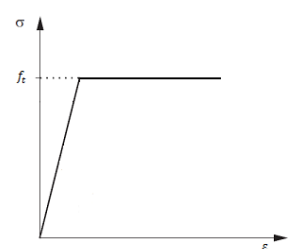

b

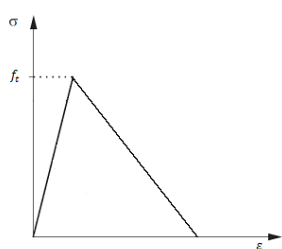

$\mathrm{c}$
Figure 23. Tensile constituitve laws: (a) elastic-brittle, (b) elastic-plastic, (c) linear tension softening

\section{F. Shear behavior}

Poisson coefficient is assumed equal to 0.2 in all the analyses following the indication of EN 1992-1-1 [9].

In software A the cracking of material causes a linear reduction of shear stiffness, from the uncracked value to the ratio $\eta_{s}\left(0<\eta_{s}<1\right)$ that represents the reduction factor corresponding to the ultimate tensile strain of the concrete and it is assumed equal to 0.2 .

Consequently a variation of the shear modulus according to the following relation is appreciated:

$$
G_{r}=\eta_{f} G_{C}
$$

where:

$G_{r} \quad$ reduced shear stiffness modulus;

$\eta_{f}$ reduction factor for the shear modulus $\left(\eta_{s}<\eta_{f}<1\right)$;

$G_{C} \quad$ initial shear stiffness modulus;

$$
G_{C}=\frac{E_{c}}{2(1+v)}
$$

In software B the decrease of shear modulus is operated using the Kolmar's law (1986) [21] that has a hyperbolic shape or choosing, as done in the present work, a constant shear reduction factor, $\eta_{f}=0.2$.

In software $\mathrm{C}$ a constant shear reduction factor $\eta_{f}=0.2$ is applied in analogy to software B.

\section{REBARS MODELS}

Software A allows modelling the reinforcement only in discrete form but in two different ways:

a) the user creates lines dedicated to reinforcement called rebar lines (see figure 24-a). The software then searches the intersections between the rebar lines and 2D elements edges creating in these points new nodes. Bar elements (trusses) are connected to these new nodes and finally rigid link conditions are created between bar nodes and 2D elements ones (see figure 24-b).

b) the user can connect discrete bar elements directly to the nodes belonging to $2 \mathrm{D}$ elements.

Software B and C allow modelling the reinforcement by means of discrete truss elements as seen in point $b$ of previous paragraph or using smeared reinforcement in which the stiffness of the bars is smeared homogeneously on a chosen set of $2 \mathrm{D}$ elements.
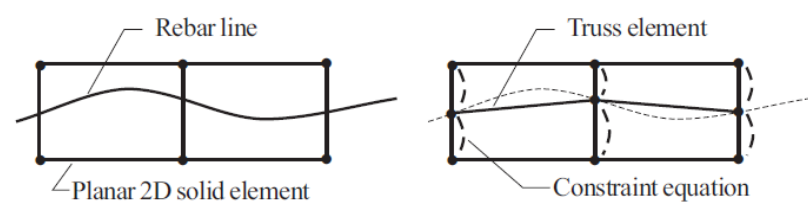

(a) before model generation; (b) After model generation

Figure 24. Rebar elements

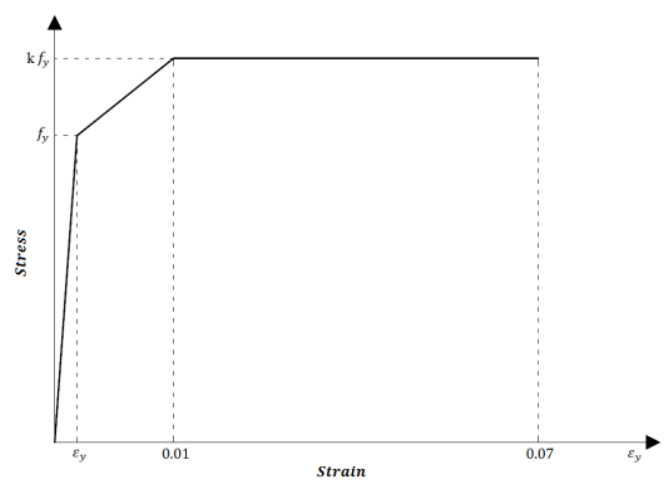

Figure 25. Trilinear stress-strain law of reinforcement

Steel is modeled as a Von Mises plastic material with a trlinear stress-strain law. The first segment is elastic $\left(E_{s}\right)$ until the yield stress, $\mathrm{f}_{\mathrm{y}}$. The second is a hardening part up to the stress $\mathrm{kf}_{\mathrm{y}}$ corresponding to a strain equal to $\varepsilon=0.01$. The last segment is perfectly plastic until the ultimate strain $\varepsilon=0.07$ (see Figure 25). This relation is valid both for tension and compression.

\section{RESULTS DISCUSSION}

Each structure has been modelled three times with each software reaching a total of $16 \times 3 \times 3=144$ analyses.

The first time using an elastic-brittle behaviour in tension, the second time using an elastic-plastic behaviour in tension and the third one trying to best fit the experimental loaddisplacement curve calibrating the linear tension softening as explained in point $\mathrm{E}$ of previous paragraph.

A first year Ph.D. student in structural engineering was chosen to perform all the numerical simulations in order to have the same approximation due to the human factor in all the runs.

The level of knowledge of the Ph.D. student in the field of non linear analysis is estimated by the authors to be similar to the one of a good civil engineer.

The test was not performed in "blind conditions": the student knew the experimental results before starting the numerical simulations.

The range of variation of the ratio between the numerical prediction $\left(\mathrm{P}_{\mathrm{NUM}}\right)$ of failure load and the experimental one $\left(\mathrm{P}_{\mathrm{EXP}}\right)$ is listed in Table 1.

The range of variation of the ratio between the numerical prediction $\left(D_{\mathrm{NUM}}\right)$ of the maximum displacement of the structure at failure and the experimental one $\left(D_{\text {EXP }}\right)$ is listed in Table 2.

For each structure and program, the lower and upper bounds of the results correspond to the tensile elastic-brittle and elastic-plastic models. 
It can be observed that these two limit models do not necessarily bound the experimental failure load (i.e. structures WT6, WT7, Mblee1, B2.03) or the experimental failure displacement (i.e. structure B2.03).

At the bottom of each table the mean values and the standard deviations of lower and upper bounds are presented.

It can be appreciated that a good accuracy has been reached in the prediction of ultimate load, whereas a very poor one is achieved in predicting ultimate displacements.

TABLE 1. FAILURE LOADS RATIOS $\mathrm{P}_{\mathrm{NUM}} / \mathrm{P}_{\mathrm{EXP}}$

\begin{tabular}{lccc}
\hline Structure & SW A & SW B & SW C \\
\hline WT2 & $0.88-0.90$ & $0.97-1.03$ & $0.81-0.89$ \\
WT3 & $1.03-1.03$ & $1.13-1.19$ & $0.97-1.03$ \\
WT4 & $0.94-0.95$ & $1.14-1.14$ & $0.74-1.06$ \\
WT6 & $1.23-1.26$ & $1.18-1.26$ & $1.01-1.21$ \\
WT7 & $1.17-1.08$ & $1.16-1.16$ & $1.00-1.12$ \\
Mb1aa & $0.96-1.01$ & $1.20-1.20$ & $1.00-1.10$ \\
Mb1ae & $0.94-0.96$ & $1.08-1.18$ & $0.94-1.11$ \\
Mb1ee & $0.96-1.00$ & $1.09-1.21$ & $1.05-1.21$ \\
Mb1ee1 & $1.04-1.04$ & $1.08-1.20$ & $1.10-1.08$ \\
Mb4ee & $0.96-1.02$ & $1.14-1.14$ & $1.00-1.13$ \\
B2.0A.4 & $1.11-1.10$ & $1.28-1.33$ & $0.95-1.10$ \\
B3.0A.4 & $1.05-1.00$ & $1.29-1.29$ & $0.91-1.05$ \\
B2.01 & $0.97-0.91$ & $1.01-1.19$ & $0.94-0.86$ \\
B3.01 & $1.08-1.09$ & $1.20-1.30$ & $0.95-1.10$ \\
B2.03 & $1.11-1.13$ & $1.14-1.36$ & $1.00-1.07$ \\
SW11 & $0.91-0.99$ & $1.01-1.07$ & $0.80-0.89$ \\
\hline Mean value & $\mathbf{1 . 0 2} \mathbf{- 1 . 0 3}$ & $\mathbf{1 . 1 3 - 1 . 2 0}$ & $\mathbf{0 . 9 5 - 1 . 0 6}$ \\
Standard deviation & $\mathbf{0 . 1 0 - 0 . 0 9}$ & $\mathbf{0 . 0 9} \mathbf{- 0 . 0 9}$ & $\mathbf{0 . 0 9} \mathbf{- 0 . 1 0}$ \\
\hline
\end{tabular}

TABLE 2. MAXIMUM DISPLACEMENT AT FAILURE RATIOS $\mathrm{D}_{\mathrm{NUM}} / \mathrm{D}_{\mathrm{EXP}}$

\begin{tabular}{lccc}
\hline Structure & SW A & SW B & SW C \\
\hline WT2 & $0.56-0.29$ & $0.38-0.29$ & $0.85-0.21$ \\
WT3 & $1.33-1.00$ & $1.22-1.00$ & $1.33-0.78$ \\
WT4 & $1.25-0.58$ & $0.96-0.67$ & $1.29-0.46$ \\
WT6 & $0.54-0.32$ & $0.39-0.25$ & $0.69-0.26$ \\
WT7 & $0.54-0.50$ & $0.60-0.37$ & $0.65-0.35$ \\
Mb1aa & $1.27-0.87$ & $2.04-1.55$ & $1.84-0.82$ \\
Mb1ae & $1.27-0.85$ & $1.79-1.05$ & $1.95-1.56$ \\
Mb1ee & $1.04-0.79$ & $1.58-1.46$ & $1.61-1.58$ \\
Mb1ee1 & $0.73-0.56$ & $0.86-1.08$ & $1.22-0.83$ \\
Mb4ee & $1.03-0.89$ & $1.99-1.63$ & $1.68-1.51$ \\
B2.0A.4 & $2.30-1.27$ & $2.40-1.87$ & $1.43-1.13$ \\
B3.0A.4 & $1.36-0.69$ & $1.47-0.97$ & $0.87-0.63$ \\
B2.01 & $1.12-0.67$ & $0.86-0.86$ & $2.76-0.51$ \\
B3.01 & $0.90-0.57$ & $0.74-0.60$ & $1.48-0.46$ \\
B2.03 & $0.89-0.39$ & $0.46-0.48$ & $1.54-1.16$ \\
SW11 & $0.95-0.55$ & $1.25-0.40$ & $1.22-0.56$ \\
\hline Mean value & $\mathbf{1 . 0 7 - 0 . 6 7}$ & $\mathbf{1 . 1 9}-\mathbf{0 . 9 1}$ & $\mathbf{1 . 4 0 - 0 . 8 0}$ \\
Standard deviation & $\mathbf{0 . 4 3 - 0 . 2 6}$ & $\mathbf{0 . 6 4}-\mathbf{0 . 5 1}$ & $\mathbf{0 . 5 3 - 0 . 4 6}$ \\
\hline
\end{tabular}

\section{CONCLUSIONS}

The present paper has analysed the uncertainties of the outcome of several non-linear analysis taking into account the use of three different softwares and the variation of only one material parameter: the tensile mono-axial behaviour after cracking.
Non-linear FEM models are numerical approximation of reality and their use gives rise to big issues on their affidability and on the safety coefficient that should be applied if they are used in design of structures.

Quite good accuracy and small scattering of the results has been achieved on the prediction of ultimate load, whereas very wide scattering of the results has been found on deformability evaluation. Further development of the research will consider the influence of more FE model parameters on the prediction of the structural response.

\section{REFERENCES}

[1] Fédération internationale du béton fib, "fib Model Code for Concrete Structures”, Berlin Wilhelm Ernst \& Sohn, 2013

[2] B. Belletti, C. Damoni and M. A. N. Hendriks, "Development of guidelines for nonlinear finite element nalyses of existing reinforced and pre-stressed beams". European Journal of Environmental and Civil Engineering, vol. 15 no. 9, pp. 1361-1384, 2011

[3] D. L. Allaix, G. Bertagnoli, V. I. Carbone and G. Mancini, "A comparison of finite element solutions for $2 \mathrm{~d}$ reinforced concrete structures". The Fourth International fib Congress 2014, Mumbai, February 2014, vol. I, pp. 265-269

[4] H. Schlune, M. Plos, and K. Gylltoft, "Safety formats for non-linear analysis of concrete structures". Magazine of Concrete Research, vol. 64 no. 7, pp. 563-574, 2012

[5] F. Leonhardt and R. Walther, "Wandartige Träger", Deutscher Ausschuss Fur Stahbeton, vol. 178, Ernst \& Sohn, Berlin, Germany, 1966

[6] S. J. Foster and R. I. Gilbert, "Tests on High Strength Concrete Deep Beams". School of Civil Engineering, The University of New South Wales, July 1993, UNICIV Report No. R-354, 87 pp.

[7] I. D. Lefas and M. D. Kotsovos, "Behaviour of reinforced concrete structural walls: strength, deformation characteristics and failure mechanism”. ACI Structural Journal, vol. 87, pp. 23-31, 1990

[8] J. B. Filho, "Dimensionamento e Comportamento do Betao Estrutural em Zonas com Descontinuidades", Tese submetida para a obtencao do grau de doctor em Engegneria Civil, Universidade Tecnica de Lisbona, Maio 1995

[9] Comitè Europèen de Normalisation, EN 1992-1-1:2004 Eurocode 2: Design of concrete structures - Part 1-1: General rules and rules for buildings

[10] Comité Euro-International du Bèton, "CEB-FIP Model Code 1990: Design Code”, Thomas Telford

[11] E. Thorenfeldt, A. Tomaszewicz and J. Jesen, "Mechanical properties of high-strength concrete and applications in design", Proc. Symp. Utilization of High-Strength Concrete, pp. 149-159, 1987

[12] F. J. Vecchio and M. P. Collins, "Compression response of cracked reinforced concrete", Journal of Structural Engineering, vol. 119, no. 12, pp. 3590-3610, 1993

[13] J. Kolleger and G. Mehlhorn, "Experimentelle und Analytische Untersuchungen zur Aufstellung eines Materialmodels fuer Gerissene Stahbetonscheiben", Forschungsbericht, Massivbau, Gesamthochs, no. 6, 1988

[14] R. G. Selby and F. J. Vecchio, "Three-dimensional Constitutive Relations for Reinforced Concrete”. Tech. Rep. 93-02, Univ. Toronto, dept. Civil Eng., Toronto, Canada, 1993

[15] S. S. Hsieh, E. C. Ting and W. F. Chen, "An Elastic Fracture Model for Concrete", Proceedings, 3rd Engineering Mechanics Division Specialists Conference, ASCE, Austin, TX, pp. 437-440, 1979

[16] F. J. Vecchio and M. P. Collins, "The modified compression field theory for reinforced concrete elements subjected to shear", ACI Journal, vol. 83, no. 22, pp. 219-231, 1986

[17] H. B. Kupfer and H. K. Gerstle, "Behavior of Concrete under Biaxial Stresses", Journal Engineering Mechanics Division, vol. 99, no.4, 1973

[18] R. De Borst and P. Nauta, "Non-orthogonal cracks in a smeared finite element model", Engineering Computations 2, pp. 35-46, 1985

[19] H. R. Riggs and G. H. Powell, "Rough crack model for analysis of concrete", J. Eng. Mech. Div., ASCE, vol. 112, no. 5, pp. 448-464, 1986.

[20] J. G. Rots, "Computational Modeling of Concrete Fracture", PhD thesis, Delft University of Technology, 1988

[21] W. Kolmar, "Beschreibug der Kraftiibertragung iiber Risse in nichtlinearen Finite-Element-Berechnungen von Stahlbetontragwerken, Dissertation", Techn. Hochschule Darmstadt, 1986 